\title{
Revisiting international business theory: A capabilities-based theory of the MNE
}

John Cantwell

Editor-in-Chief

Journal of International Business Studies (2014) 45, I-7. doi: I0.1057/jibs.2013.6।

\section{THE EVOLUTION OF DAVID TEECE AS A SCHOLAR}

We begin this issue with a Perspectives article by David Teece. David Teece was recently elected as the AIB Fellows Eminent Scholar, for which he was honored at a special plenary session of the AIB Conference in Istanbul in July 2013, and at which session he presented an earlier version of the paper we publish here. A very much earlier forerunner of this paper was also presented at another plenary session organized by Christos Pitelis at the AIB Annual Conference in Nagoya in June 2011. The AIB Fellows Eminent Scholar award honors a leading academic who has had a strong and considerable influence on scholarship in the international business (IB) field, while not himself or herself being a regular member of the AIB community. David Teece is well known as a preeminent figure in the business strategy field, whose work has considerably influenced the IB research of many of us. What may not be quite so well known in our community is that David is also a business leader. He is probably the only person in the world who would be qualified to be elected as the AIB Fellows International Executive of the Year, as well as Eminent Scholar! One thinks in this context of David Ricardo, who in the early nineteenth century was both a business leader and the greatest scholar of his era in the field of political economy. Yet in those days it was not uncommon to combine the worlds of practice and scholarly writing. With the far greater specialization required to master a domain these days, the skillsets needed for business success and academic success are very different in many ways, so to be a leader in both areas is a quite remarkable achievement.

It is no accident that David Teece has now turned his mind to issues of IB theory; indeed, to be more accurate he now returns to and revisits IB theory. Some younger IB scholars today may be unaware of this, but David Teece was one of the pioneers of the IB field as a student and then a young scholar himself between the early 1970s and mid-1980s. For those of us such as myself who entered the field in the 1980s, Teece's papers, and especially his 1977 articles in the Economic Journal and Management Science (Teece, 1977a,b) greatly affected the way in which we thought about the subject. The early Teece was fascinated with the questions raised by the topic of international technology transfer before it became fashionable; his insights in these papers remain important even today, and they are worth (re-)reading. 
In particular, Teece's analysis made clear that there needed to be two sides to transaction cost reasoning about international technology transfer and the existence of the multinational enterprise (MNE). Most other transaction cost economists of that period stressed that aspect of technology which was associated with potentially public knowledge and could therefore be thought of as akin to information being costly to create, but relatively easy to transfer or to re-use in the manner of a public good. In this view, the primary concern was that such knowledge may leak out to free riders, so the MNE internalized the (potential) market for the international transfer of technological knowledge to ensure the greater appropriability of returns on investments in knowledge creation. Instead, Teece called our attention to the other aspect of technology which was associated with operational capabilities typically embedded within organizations, and which aspect may make technology transfer a difficult and costly process. In this case the MNE extends its own operations internationally since it is less costly and more effective for it to reproduce its own capabilities in a subsidiary company than it would be to try and inculcate them in an independent organization abroad that (in our current terminology) lacked the relevant absorptive capacity. In other words, what Teece showed was that the existence of the MNE depends upon the differentiated character of its own capabilities, and not just on the establishment of an appropriate governance structure. So it was at least implicit in Teece's early writings that IB theory needed to be built through a combination of arguments about capabilities as well as governance structures.

In the meantime, after that early foray into the world of IB theory, David Teece moved on into mainstream business strategy research, to examine the conditions under which firms profit from innovation and to develop the concept of dynamic capabilities. Indeed, his work on dynamic capabilities now forms the foundation of a good proportion of the literature in strategic management. As with any innovative stream of research, not every strategy researcher uses the construct of dynamic capabilities. Indeed, among those that do, we can find different interpretations or schools of thought (see, e.g., Peteraf, Di Stefano, \& Verona, 2013). However, every strategy researcher worth their salt now has an opinion on the concept of dynamic capabilities. This marks a high degree of influence of such capability-based reasoning in debates in the strategy field. In his JIBS article here, David Teece brings the ideas of dynamic capabilities back to the IB literature and to the theory of the MNE, and so in a sense he has now come round full circle as a scholar. He is well positioned to do so, since while he has been away from the IB field for some time, he knows from his earlier interests in the area how some of his new ideas might be built on to past and extant thinking in IB, and how one might go about better integrating or re-integrating some of the key concepts used in our field.

\section{HOW TEECE'S NEW APPROACH CONNECTS TO RECEIVED IB THEORY}

The relationship between Teece's new perspective and extant IB theory might be conveniently expressed with reference to the eclectic paradigm, the framework that synthesizes different theoretical approaches to IB (Dunning, 1988, 2000). As is well known, the eclectic paradigm distinguishes between influences on IB activities associated with ownership advantages $(\mathrm{O})$, that is, the nationality of ownership of firms engaged in IB, internalization advantages (I) which affect the boundaries of the MNE, and location advantages (L) of the place(s) in which IB activities are sited. Hence, the eclectic paradigm was essentially about how to appropriately combine issues of capabilities $(\mathrm{O})$, transaction costs (I), and because of the international dimension of IB which distinguishes it from a mere theory of the firm in general, the resources, capabilities and institutions of locations as host production sites (L). For our current purpose it is vital to appreciate that from the outset Dunning's eclectic paradigm recognized the collective character of many capabilities in its $\mathrm{O}$ and $\mathrm{L}$ components. The capabilities referred to as $\mathrm{O}$ advantages, due to the nationality of ownership of MNEs, incorporated not just the capabilities of the MNE itself, but those of the business networks of which it was a part in their home country, and which external capabilities were associated with the relative strengths of home country institutions. The capabilities that constitute one element of L advantages refer to the capabilities of relevant business networks in the host country, which together with other host country factors (such as taxation or regulatory structures, or the extent of the local market) help to attract or repel IB activities in that place. It can be noted in passing that the conceptual boundaries are placed somewhat differently in Dunning's eclectic paradigm compared to Rugman and Verbeke's (1992) subsequent framework of firm-specific advantages and country-specific advantages.

With the benefit of hindsight, the terminology of "ownership" in the $\mathrm{O}$ advantages prong of the eclectic paradigm may have been unfortunate since 
it is open to misinterpretation. While it refers to the "nationality of ownership" or the home country of origin of the MNE, and so concerns home country strengths or weaknesses as well as the capabilities of the individual firm itself, it might be naturally misunderstood as referring to the "ownership of assets". This may have become quite a common misinterpretation by virtue of the empirical definition of the MNE, which was typically based on the criterion of the international ownership (and thereby control and management) of income-generating assets. However, the MNE does not necessarily have to be defined in the traditional way in terms of the ownership of assets internationally. In his later writings, Dunning had defined the MNE more generally as the coordinator or orchestator of international business networks. This broader definition of what constitutes the MNE, to incorporate the external networks over which the MNE has some degree of control, is reflected in, for example, Dunning and Lundan (2008) or Cantwell, Dunning and Lundan (2010), and it is implicit in a good deal of the stream of research on global value chains (e.g. Mudambi, 2008). There are of course measurement problems entailed in suitably capturing this broader conceptualization in an empirical analysis of the span of MNE activity, such as its profile of technological accumulation (as reflected, e.g., in its patent holdings), but at least from a theory viewpoint it is well accepted that capability building relies on a nexus of reciprocal relationships that are less and less well defined by the boundaries of ownership. A similar issue has long been evident in the theory of what is foreign direct investment (FDI), which depends on the exercise of managerial control and influence, in contrast to what is defined as FDI by statisticians, of necessity using the criteria of ownership (equity stakes).

A general theory of the MNE should incorporate the role of the continuous interaction between firm capabilities and host location level capabilities, which entails the management or orchestration of an interaction between home and host country capabilities and knowledge too. Reasoning in this way, we can appreciate that a capabilities-based approach to domestic firms might be thought of as a special case of the explanation of the capabilities theory of the MNE. It is a special case in which firms rely on interaction with capability formation in just a single location, or at most the spread of locations considered are sub-national regions, so locational variation is more limited. Note that this is very different from the traditional internalization approach to the boundaries of the firm, in which location is usually regarded as exogenous and largely irrelevant to the determinants of the extent of the firm, and so the theory of "the firm" itself becomes what is believed to be the general category as a more abstract entity, regardless of whether it happens to be an MNE or a domestic firm - so the theory of the MNE becomes a special case of the more general analysis of the firm. That is, the distinction between an MNE and a domestic firm requires an entirely separate theory of location that has nothing to do with the theory of the firm as such. Instead, as Teece argues here, the MNE constitutes an organizational platform that straddles and draws upon a variety of specific national innovation systems (NISs) and regional innovation systems (RISs) to derive, utilize and develop combined capabilities. Moreover, since some degree of hierarchy and home country concentration of some key activities remains typical within the MNE, the interaction of the MNE with home country capabilities and with host country capabilities raise different considerations. So the MNE is also more than just a multilocation firm, since its cross-border organizational structure affects the varying nature of its relationship with locations (Beugelsdijk \& Mudambi, 2013).

\section{A CAPABILITIES-BASED APPROACH IN IB}

Thus, a capabilities-based approach is central to distinguishing the theory of the MNE from a mere special case of a theory of the firm. The capabilities on which an MNE and its international business network draws derive from home country institutions and host country expertise as well as directly from within the firm itself. From a host locational standpoint, economic geographers refer to the capabilities of clusters, regions, countries or other areas held across a variety of firm and non-firm actors. The idea of an NIS or RIS relies on a notion of locally interdependent capabilities that are geographically bounded. In the eclectic paradigm, building new capabilities therefore derives from an interaction between $\mathrm{O}$ and $\mathrm{L}$ capabilities: those that are due to the firm and its home country institutions $(\mathrm{O})$ on the one hand, and those that are due to other actors in host locations in the rest of the world (L) on the other. This dynamic and continuous cross-border interaction is particular to MNEs, which develop integrative and combinatorial capabilities specifically for this purpose. As Teece suggests, business networks define the span of capabilities that may be used, around the locus of an MNE. But the combinatorial capacity that connects locationally differentiated capabilities is specific to the MNE (as opposed to a purely domestic firm). This integrative role has 
become especially significant with the emergence and growth of competence-creating subsidiaries (Cantwell \& Mudambi, 2005), since in these more innovative knowledge-seeking nodes entrepreneurial initiatives can have an international reach and are better able to draw on multiple sources of capabilities across different locations. In Teece's proposed framework we might think of these new centers as entailing the development of dynamic capabilities at a subsidiary level, and in the local network in which a subsidiary is embedded.

MNEs have distinct capabilities that enable them to link knowledge and innovation components drawn from different locational contexts. They build and connect synergistic or complementary locational portfolios of capabilities (Cantwell, 2009). MNEs are therefore often crucial to the vitality and health of a location by connecting it effectively to distant international sources of complementary specialized knowledge and expertise, and in the process building and discovering new opportunities for themselves as well as others; as well as drawing capabilities from the location itself. Domestic firms have the latter feature too, but not the former. As sources of knowledge and innovation become ever more complex and globally dispersed, so the MNE becomes the key builder and facilitator of international capability development. Without the MNE, locations are liable to become cut off from the international knowledge and innovation connections they need, and so MNEs facilitate the process of sustaining competitiveness at a locational level through the creation of relevant pipelines (Lorenzen $\&$ Mudambi, 2013). From the standpoint of building competitive advantage for the firm itself, MNE capabilities are more than just the sum of the individual locational parts. The competitiveness of the MNE relies on a process of continuous inter action between multiple elements obtained from different parts of its international network which create novel applications in ways that would have been far less likely to arise had the contributory elements each remained within their own original contexts. This process does not necessarily require that an existing capability be moved in its entirety from one location to another, as in the traditional conceptualization of international technology transfer. Rather, more commonly contemporary international innovation implies the development of an understanding that some aspects of the knowledge used to tackle a problem found in a given setting may be useful in resolving a quite different problem or creating a new opportunity in a quite different context, thereby leading to a valuable new application not previously envisaged.

Teece shows how the new capabilities-based view that he sets out draws upon or can be rendered consistent with the earlier IB perspective on governance structures - but which new view also moves beyond some of the limitations of that original perspective, to extend the scope and the power of the analysis. In many ways there is some similarity here with the synthesis that the eclectic paradigm has attempted to provide in a wider context in IB, beyond the theory of the firm or the MNE as such. The eclectic paradigm aimed to provide a framework that would enable us to recognize the connections between apparently disparate IB theories, and where appropriate how they might be synthesized, or for that matter the circumstances under which they can be seen to represent alternative interpretations of a common phenomenon. The key to achieving this integrative and comparative goal is to find the appropriate way of combining ideas taken from different origins (including those taken from different disciplines, which more complex form of theoretical combination has become increasingly common as well as vital in IB scholarship), rather than isolating each branch of thought considered solely on its own terms, and thereby rendering the risk of creating and preserving intellectual silos or sparking off largely unnecessary artificial feuds.

\section{A CONTRIBUTION TO EVOLUTIONARY AND MULTIDISCIPLINARY APPROACHES TO IB}

Teece's argument that explaining competitive advantage requires a multidisciplinary approach is important, and deserves emphasizing. The earlier theories of the MNE derived more or less exclusively from Economics, and internalization theory especially was grounded on a critique of neoclassical economics that accepted most of its premises. It was grounded on the same exchange-based, choice theoretic framework and relied on a similar methodological individualism. A return to a wider political economy approach incorporating institutional considerations is inherently multidisciplinary in modern terms, although it follows in the traditions of classical political economy until the mid-nineteenth century, these days re-emerged under the umbrella of evolutionary economics (Nelson \& Winter, 1982; Rosenberg, 1982). While contemporary mainstream economists tend to design assumptions in large part in order to make their formal models tractable, and then suppose that if model behavior can emulate real-world behavior the world behaves "as if" the 
assumptions were true (following the tradition of Friedman, 1953), whereas evolutionary economists design assumptions to themselves capture some essential aspect of real-world behavior directly, drawn from appreciative theorizing that is grounded on a keen empirical, historical and institutional understanding of the relevant processes (what used to be called the "stylized facts"). Thus, as Nelson (1998) has argued, in evolutionary economics appreciative theory tends to lead the way analytically, which of course is more akin also to the way in which theory development tends to proceed in strategic management and in most current research in international business. In the context of Teece's perspective here, artificial departures from reality (of the kind found in some of the older theoretical models of the MNE, such as in the hypothetical notion of the supposed internalization of a market in a context in which no market had ever existed) become unnecessary once the starting point is the real-world capabilities from which both firms and markets can be created and built alongside one another.

In an evolutionary perspective, business strategy should have an experimental element, to allow for variety in the approaches adopted owing to uncertainty over their outcomes. In this context, it is important to understand that traditional IB approaches have most often taken an outcome-driven perspective (as indeed has much of the social sciences more widely), rather than analyzing an unfolding and open process of change over time, which process has an identifiable path or direction but not necessarily a well-defined eventual outcome. The capabilities represented in $\mathrm{O}$ advantages can only be properly understood as evolving through a continuous process over time in which they are always in flux and in a state of change, revision and improvement (or decline), rather than by the outcome of that process in the form of, for example, some given set of intangible assets held at a particular point in time. The need for experimentation or trial and error in capability formation immediately implies that a mechanism for change is built in (as it is in Darwinian natural selection), since variety ensures that adaptation to any change in the social or industrial environment (or the ecosystem, as Teece terms it) becomes easier across the system as a whole, and better options emerge through their selection according to their revealed fitness with the environment, rather than being somehow optimally selected in advance. However, this kind of evolutionary selection always tends to retain some continuing variety across firms or MNEs, associated with shifts in the relative shares of activity accounted for by alternative paths or strategies, rather than completely eliminating or driving out all strategies apart from one dominant type - and so the retention of variety thereby preserves the capacity of the system to adjust to future changes as well. This may also help to account for the distributions of practice (behind best practice) that Teece observes, which imply some capacity to survive in a weaker form when current fitness is poor but not disastrous.

An interpretation of Teece's argument which would further bring out the evolutionary character of his argument might be constructed as follows. What he calls ordinary capabilities are adequate in an environment in which there is little change or innovation, and technology is fairly stable. This is also the kind of world in which conventional economics and in IB internalization theory in isolation can work reasonably well. However, as innovation occurs, and technology and the environment and the relevant ecosystem change, ordinary capabilities are insufficient and do not provide the means required either for entrepreneurial change from within, or even for the capacity to successfully adapt passively to external change. The real world in which firms operate is generally represented by this kind of continual change, and so theories that use a comparative static methodology to examine change as an occasional phenomenon associated with specific events or a kind of intermittent exogenous shock are inherently unrealistic, or at best merely partial snapshots of a deeper underlying process. The capacity of MNEs to adapt, and in the social context not merely to adapt but to themselves initiate the reconfiguration and transformation of their environment, is given by their dynamic capabilities.

The contemporary understanding of the MNE as embedded in an evolving business network enhances the technological accumulation perspective (Cantwell, 1989), since the logic of that perspective was not driven by a rationale of ownership as such. However, it may undermine the particular application of an evolutionary approach suggested by Kogut and Zander (1993) in their conceptualization of the distinctive separation, unique identity and specificity of social groups in the sociology of knowledge transfer and combinatorial capabilities. Indeed, such social groups may be as subject to the generation of conflicts and rent-seeking activities that inhibit knowledge sharing as they are to the creation of shared values that promote the capacity for knowledge sharing and combination (Mudambi \& Navarra, 2004). What is now evident, and indeed emphasized in some of 
Kogut's more recent social network research in the strategy literature (beyond IB), is that such social groups can just as easily be thought of as relational networks, and there is now of course much evidence on the role of prevailing group ties in external as well as internal networks. Yet if this is so, there are no grounds for necessarily supposing that an internal network tie within the MNE is always stronger and more effective than an external link. These days if we focus (as they did) on the advantages of combinatorial capabilities, we may typically argue that selectively combining internal and external expertise is more likely to generate novelty and creativity than would relying on internal expertise alone. So one might well adopt their argument about the benefits of consistent social interaction but reach a very different kind of conclusion on the logic for the existence and nature of the MNE - as an orchestrator of complementary internal and external networks (Cantwell, 2013), rather than as an independent social community.

\section{A FINAL WORD ON THE VALUE OF PERSPECTIVES ARTICLES IN IIBS}

In recent years we have published relatively few articles in the Perspectives category in JIBS, and we would like to have more. The article in this issue by David Teece is a perfect exemplar of what we are looking for in this respect. It may be worth briefly elaborating on this theme, since I have quite often been asked whether IIBS welcomes Perspectives submissions (we do), and some confusion may have arisen over the fact that we do not accept papers that are (just) literature reviews. A Perspectives paper does much more than just review the relevant literature as would a regular article in the Original Manuscript or Research Note categories of submissions although what a paper does beyond the literature review is different in the case of each submission category. We expect a Perspectives article to synthesize the literature in some novel way, and to critically evaluate it so as to offer a new perspective on it (hence the label) and suggest new research direction (s). The paper by David Teece achieves this objective wonderfully well. A Perspectives paper must make and clearly identify its contribution to our theory and conceptualization of IB, just like any other JIBS article, and it is reviewed to the same standards as any other article. Thus, as we state in our description of this article category:

Perspectives must have the same rigor, style and tone as articles; should identify relevant prior research; clearly articulate their contribution to international business research; and provide compelling evidence for their arguments.

It should not need saying, but since I have encountered questions which seem to suppose otherwise, Perspectives submissions are not specially invited by the Editor-in-Chief of the journal, any more than are submissions in the other categories. Appropriate submissions are always welcome in JIBS, from whomever they come and in whichever of the recognized submission categories they fall, and we have no inside track. Whenever they are accepted, Perspectives articles can appear throughout the year in any issue of the journal - the occasional special issues we run are organized by specific topics or themes, not by article category. In the current issue, we open with Teece's paper and close with another Perspectives article by Peter Buckley, in which he considers the relevance of Adam Smith's theory of knowledge for contemporary IB theory and practice. Since the Decade Award retrospective is also a particular form of Perspectives paper, it is to be hoped that this first issue of the new year will illustrate and underline our continued and renewed commitment to this article submission category.

\section{REFERENCES}

Beugelsdijk, S., \& Mudambi, R. 2013. MNEs as border-crossing multi-location enterprises: The role of discontinuities in geographic space. Journal of International Business Studies, 44(5): 413-426.

Cantwell, J. A. 1989. Technological innovation and multinational corporations. Oxford: Basil Blackwell.

Cantwell, J. A. 2009. Location and the multinational enterprise. Journal of International Business Studies, 40(1): 35-41.

Cantwell, J. A. 2013. Blurred boundaries between firms, and new boundaries within (large multinational) firms: The impact of decentralized networks for innovation. Seoul Journal of Economics, 26(1): 1-32.

Cantwell, J. A., Dunning, J. H., \& Lundan, S. M. 2010. An evolutionary approach to understanding international business activity: The co-evolution of MNEs and the institutional

environment. Journal of International Business Studies, 41(4): 567-586.

Cantwell, J. A., \& Mudambi, R. 2005. MNE competence-creating subsidiary mandates. Strategic Management Journal, 26(12): 1109-1128.

Dunning, J. H. 1988. The eclectic paradigm of international production: A restatement and some possible extensions. Journal of International Business Studies, 19(1): 1-31.

Dunning, I. H. 2000. The eclectic paradigm as an envelope for economic and business theories of MNE activity. International Business Review, 9(2): 163-190.

Dunning, J. H., \& Lundan, S. M. 2008. Multinational enterprises and the global economy. Cheltenham: Edward Elgar.

Friedman, M. 1953. Essays in positive economics. Chicago: University of Chicago Press. 
Kogut, B., \& Zander, U. 1993. Knowledge of the firm and the evolutionary theory of the multinational corporation. Journal of International Business Studies, 24(4): 625-645.

Lorenzen, M., \& Mudambi, R. 2013. Clusters, connectivity and catch-up: Bollywood and Bangalore in the global economy. Journal of Economic Geography, 13(3): 501-534.

Mudambi, R. 2008. Location, control and innovation in knowledge-intensive industries. Journal of Economic Geography, 8(5): 699-725.

Mudambi, R., \& Navarra, P. 2004. Is knowledge power? Knowledge flows, subsidiary power and rent-seeking within MNCs. Journal of International Business Studies, 35(5): 385-406.

Nelson, R. R. 1998. The agenda for growth theory: A different point of view. Cambridge Journal of Economics, 22(4): 497-520.

Nelson, R. R., \& Winter, S. G. 1982. An evolutionary theory of economic change. Cambridge, MA: Harvard University Press.
Peteraf, M., Di Stefano, G., \& Verona, G. 2013. The elephant in the room of dynamic capabilities: Bringing two diverging conversations together. Strategic Management Journal, 34(12): 1389-1410.

Rosenberg, N. 1982. Inside the black box: Technology and economics. Cambridge: Cambridge University Press.

Rugman, A.M., \& Verbeke, A. 1992. A note on the transnational solution and the transaction cost theory of multinational strategic management. Journal of International Business Studies, 23(4): 761-771.

Teece, D.J. 1977a. Technology transfer by multinational firms: The resource cost of transferring technological know-how. The Economic Journal, 87(346): 242-261.

Teece, D.J. 1977b. Time-cost tradeoffs: Elasticity estimates and determinants for international technology transfer projects. Management Science, 23(8): 830-837. 